\title{
DIFFERENTIAL CELL COUNT AS DIAGNOSTIC AND PROGNOSTIC MARKER OF ACUTE MYOCARDIAL INFARCTION
}

\author{
Sri Anita, Liong Boy Kurniawan, Darwati Muhadi \\ Department of Clinical Pathology, Faculty of Medicine, Hasanuddin University/Dr Wahidin Sudirohusodo Hospital, Makassar, \\ Indonesia. E-mail: srianitasiradjuddin@yahoo.com
}

\begin{abstract}
Myocardial infarction is a necrosis of myocardial cells due to lack of blood and oxygen supply caused by obstruction of coronary arteries, mostly due to atherosclerosis processes. Increased inflammatory marker level is associated with poor cardiovascular prognosis. This study was aimed to know whether leukocytes count, differential cell count and the Ratio of Neutrophils-Lymphocytes (RNL) could distinguish between types of Acute Myocardial Infarction (AMI) and to evaluate its correlation with mortality. This was a crosssectional retrospective study using medical records patients which were diagnosed as AMI by clinicians in Cardiac Centre of the Dr. Wahidin Sudirohusodo Hospital during the period of April $1^{\text {st }}, 2015-$ May $31^{\text {st }}, 2016$. Statistical analysis used the Mann-Whitney and Chi-Square test, $p<0.05$ was considered as significant. The total subjects were 435 patients divided into 289 ST- Elevation Myocardial Infarction (STEMI) and 146 Non-STElevation Myocardial Infarction (NSTEMI). There were significant differences in that mean of leukocytes, neutrophils, lymphocytes, monocytes, eosinophils counts and RNL between STEMI and NSTEMI $(p<0.05)$. Significant differences were also found in leukocyte, neutrophils, lymphocytes, eosinophils, basophils and RNL mean between those who died and survived $(p<0.05)$ and a significant correlation between increased leukocytes, neutrophils, basophils counts with mortality $(p<0.05)$. In conclusion, the number of leukocytes and leukocyte count can be used as diagnostic markers of AMI between STEMI and NSTEMI, as well as prognostic markers among patients who died and survived. Routine blood sampling cohort studies in patients with AMI can avoid the bias of the results obtained.
\end{abstract}

Key words: Leukocyte, differential cell count, acute myocardial infarction, mortality

\section{INTRODUCTION}

Myocardial infarction is the death of myocardial cells arising from lack of both blood and oxygen supply caused by an obstruction in one or more coronary arteries. Data from the World Health Organization (WHO) in 2016 reports that Acute Myocardial Infarction (AMI) is the major cause of morbidity and mortality in the world, accounted for 32.4 million deaths which occur due to AMI and stroke worldwide. According to the American Heart Association (AHA) in 2015, the data showed that the death rate of cardiovascular disease in the United States amounted to $31.3 \%{ }^{1,2}$

The myocardial infarction in Indonesia is the first on the list of some cases of patients hospitalized in the cardiology service centers. Basic Health Research (Riskesdas) by the Ministry of Health in 2014 reported a prevalence of coronary heart dis- ease in Indonesia based on a doctor's diagnosis or symptoms of $0.5 \%$. Mortality from ischemic heart disease in Indonesia according to WHO data is 191-541 per 100,000 males and 112-334 per 100,000 female populations (WHO, 2011). While the mortality rate of myocardial infarction at the Dr. Wahidin Sudirohusodo Hospital (RSWS) based on M. Kasim's report on the study in 1996-1997 has shown the amount to $33.58 \%{ }^{3,4}$

The majority of cases of myocardial infarction caused by atherosclerosis related coronary artery thrombosis. ${ }^{5}$ The atherosclerosis process is a chronic inflammatory process of both local and systemic in which the increasing concentration of inflammatory markers during the attack will show a high risk of ischemia in the future and is associated with poor cardiovascular prognosis. The higher the inflammatory $p$ - 
rocess, the higher the probability of plaque rupture with thrombus and embolic complications that is in the form resulting in myocardial infarction..$^{5-7}$

Several studies have shown a correlation between the numberof leukocytes in the circulation with increased cardiovascular risk. Kurniawan et al., ${ }^{7}$ in RSWS reported that AMI patients with leukocytosis have a higher risk of mortality during the treatment compared to patients with normal leukocyte counts. The role of hematologic parameters on cardiovascular disease has been investigated, including several types of inflammatory cells such as neutrophils, lymphocytes, monocytes, eosinophils and basophils associated with coronary heart disease. The influx of neutrophils that many to the network are a sign of acute inflammation, whereas chronic inflammation will be dominated by the mobilization of monocytes and lymphocytes to the sites of inflammation. Basophils produce histamine as a major mediator of fast and vascular inflammatory response. Leukocyte count (differential cell count) is the method of counting of leukocytes in the blood based on the proportion (\%), contained in the routine blood test examination which is an examination that is fast, easy, accurate and inexpensive and can also be calculated manually. ${ }^{8}$

This study aimed to analyze the number of leukocytes and differential cell count and also the ratio of neutrophils to lymphocytes in differentiating types of $\mathrm{AMI}$ and associated with mortality.

\section{METHODS}

The study was conducted with a cross-sectional retrospective approach using secondary data from medical records of hospitalized patients at diagnosis by clinicians. Then, the selection based on an acute myocardial infarction were divided into AMI with STElevation (STEMI) and AMI without ST-Segment elevation (NSTEMI) after a physical examination, ECG and laboratory in the Cardiac Centre, at the Dr Wahidin Sudirohusodo Hospital during the period April 1, 2015 to May 31, 2016. Leukocyte cell count and differential cell count were examined at the time of admission to hospital. Leukocytosis was categorized as the number leukocytes $>10 \times 10^{3} / \mathrm{mL}$, while the number of leukocytes $4-10 \times 103 / \mathrm{mL}$ was considered normal. The percentage of neutrophils was normal $=52-75 \%$, High > $75 \%$; Lymphocytes $=20-40 \%$, High $>40 \%$; Monocytes = 2-8\%, High > 8\%; Eosinophils = 1-3\%, High > 3\%; Basophils $=0-0.1 \%$, High $>0.1 \%$.

Data analysis was performed using SPSS version 21 The statistical method used was the calculation of $t$ - he mean value (mean), Standard Deviation (SD) and the frequency distribution. The purpose of Chi-Square test was to assess the differences in the distribution or the relationship between two categorical variables. The purpose of Mann-Whitney test was to compare mean values differential cell count by AMI type and exit status. The test results were statistically significant if $p<0.05$ was achieved. Research approval was obtained from the ethical appropriateness of commission Health Research Ethics (KEPK) Faculty of Medicine, University of Hasanuddin Makassar-RSWS No.Register UH16070584.

\section{RESULTS AND DISCUSSION}

This study comprised 435 patients diagnosed by clinicians suffering from AMI then they were divided into 289 patients with STEMI and 146 patients with NSTEMI, respectively who met the criteria with such characteristics in Table 1 . There were no significant gender differences by type of AMI. Furthermore, there were significant differences in the age distribution by type of AMI, the percentage of STEMI was higher at age $<50$ years, while the percentage of NSTEMI was higher at age $>50$ years. These results were consistent with the report from the Ministry of Health based on data from Health Research Association in 2013 which showed that coronary heart disease was observed at 45-54 years of age. Also, there were significant differences in the distribution of the exit status according to the type of AMI, where the percentage of death was higher in STEMI (12.5\%) than in NSTEMI (6.2\%). Similarity, these results were consistent with research conducted by Mytha and Alwi. ${ }^{5,6}$ This was due to that in STEMI total occlusion of a coronary artery causes necrosis of all or almost all layers of the heart wall while partial arterial occlusion occurred in NSTEMI, both have clinical and pathophysiological symptoms, but different degrees of severity. ${ }^{5,6}$

There was a significant difference in the mean leukocyte, neutrophils, lymphocytes, monocytes, eosinophils and RNL between STEMI with NSTEMI ( $p$ $<0.05$ ), it as shown in Table 2. In this study, leukocytes increased, this was in line with research by Abbase et al., ${ }^{9}$ so that leukocytes could be a predictor and prognostic indicator after ischemic events and myocardial infarction, leukocytes were associated with an area of infarction that occurred, impaired left ventricular function and mortality after AMI. ${ }^{9}$

In this study, a significant association was found inflammation occurring in AMI often characterized by 
peripheral leukocytosis and relatively most often is the neutrophil. This report had similarity results with Gazi et al., in this study, a significant association was found between high neutrophils with STEMI; the process of inflammation occurring in AMI often characterized by peripheral leukocytosis and relatively most often is the neutrophil. This report had similarity results with Gazi et al., in 2015. ${ }^{10}$ Neutrophils were rapidly released into the circulation in a state of acute stress and by then the lymphocytes have a significant role in modulating the inflammatory response at this stage of atherosclerosis, in acute conditions to be encountered lymphopenia. Number of neutrophil and the ratio of neutrophil-lymphocyte increase, was the same reported as a predictor of mortality in cardiovascular disorders by Abbase et al. ${ }^{9}$ There was no significant difference between the mean basophils in NSTEMI and STEMI ( $p>0.05$ ) because in both basophil histamine was issued as a primary mediator of fast and

Table 1. Characteristics of research subjects

\begin{tabular}{llcc}
\hline \multirow{2}{*}{ Characteristics } & \multicolumn{2}{c}{ Of AMI } \\
\cline { 3 - 4 } & & $\begin{array}{c}\text { STEMI } \\
\text { (N\%) }\end{array}$ & $\begin{array}{c}\text { NSTEMI } \\
\text { (N\%) }\end{array}$ \\
\hline Gender & Male & $232(80.3)$ & $108(74.0)$ \\
& Female & $57(19.7)$ & $38(26.0)$ \\
Age & $<40$ years & $14(4.8)$ & $6(4.1)$ \\
& 40-49 years & $61(21.1)$ & $15(10.3)$ \\
& 50-59 years & $113(39.1)$ & $58(39.7)$ \\
Exit status & 60-69 years & $63(21.8)$ & $42(28.8)$ \\
& Died & $36(13.1)$ & $25(17.1)$ \\
& Survived & $253(87.5)$ & $137(93.8)$ \\
\hline
\end{tabular}

vascular inflammatory response.

There was a significant difference in the mean leukocyte count, neutrophils, lymphocytes, eosinophils, basophils and RNL of those who died with survival $(p<0.05)$ (Table 3$)$. In this study, the proportion of neutrophils increased lymphocytes, which has a similar result by Abbase et al. ${ }^{9}$ Abbase in his reports claimed that the ratio of the leukocyte count and neutrophil-lymphocyte was an independent predictor of mortality of patients with acute myocardial infarction during hospitalization and has been shown to increase the risk of long-term mortality in patients with myocardial infarction and has a prognostic value. There found the ratio of the neu- trophil-lymphocyte $=5.51$ in which this value approacches the cut-off ratio of neutrophil-lymphocyte> 5.77, reported by Gazi et al. ${ }^{10}$ As a result, no significant difference was found between the mean monocyte

Table 2. Comparison of the average of leukocytes, differential cell count by type IMA

\begin{tabular}{llccrc}
\hline Variable & Type IMA & $\mathrm{n}$ & Mean & $\mathrm{SD}$ & $\mathrm{p}$ \\
\hline Leukocytes & STEMI & 289 & 13.03 & 4.48 & $0.000^{*}$ \\
$\left(\mathrm{x} 10^{3} / \mu \mathrm{L}\right)$ & NSTEMI & 146 & 11.43 & 4.72 & \\
Neutrophils & STEMI & 289 & 74.32 & 11.26 & $0.007^{*}$ \\
(\%) & NSTEMI & 146 & 70.81 & 13.13 & \\
Lymphocytes & STEMI & 289 & 16.46 & 9.02 & $0.021^{*}$ \\
(\%) & NSTEMI & 146 & 18.87 & 10.39 & \\
$\begin{array}{l}\text { Monocytes } \\
\text { (\%) }\end{array}$ & STEMI & 289 & 6.93 & 2.84 & $0.042^{*}$ \\
Eosinophils & NSTEMI & 289 & 1.56 & 2.51 & $0.030^{*}$ \\
(\%) & NSTEMI & 146 & 1.71 & 1.60 & \\
Basophils (\%) & STEMI & 289 & 0.28 & 0.56 & \\
& NSTEMI & 146 & 0.23 & 0.26 & $0.061^{*}$ \\
NLR & STEMI & 289 & 4.52 & 1.25 & \\
& NSTEMI & 146 & 3.75 & 1.26 & $0.016^{*}$ \\
\hline & & & & & \\
\hline
\end{tabular}

Table 3. Comparison average leukocytes, differential cell count by exit status

\begin{tabular}{|c|c|c|c|c|c|}
\hline Variable & Exit status & $\mathrm{n}$ & Mean & SD & $p$ \\
\hline \multirow{2}{*}{$\begin{array}{l}\text { Leukocytes } \\
\left(\times 10^{3} / \mu \mathrm{L}\right)\end{array}$} & Death & 45 & 15.16 & 6.38 & $0.001 *$ \\
\hline & Survive & 390 & 12.19 & 4.28 & \\
\hline \multirow{2}{*}{$\begin{array}{l}\text { Neutrophils } \\
(\%)\end{array}$} & Death & 45 & 76.36 & 13.26 & $0.011 *$ \\
\hline & Survive & 390 & 72.77 & 11.83 & \\
\hline \multirow{2}{*}{$\begin{array}{l}\text { Lymphocytes } \\
\text { (\%) }\end{array}$} & Death & 45 & 13.84 & 8.36 & $0.004 *$ \\
\hline & Survive & 390 & 17.67 & 9.62 & \\
\hline \multirow[t]{2}{*}{ Monocytes (\%) } & Death & 45 & 7.58 & 3.40 & $0.397^{*}$ \\
\hline & Survive & 390 & 7.11 & 2.88 & \\
\hline \multirow[t]{2}{*}{ Eosinophils (\%) } & Death & 45 & 1.09 & 1.84 & $0.004 *$ \\
\hline & Survive & 390 & 1.67 & 2.28 & \\
\hline \multirow[t]{2}{*}{ Basophils (\%) } & Death & 45 & 0.40 & 0.63 & $0.023 *$ \\
\hline & Survive & 390 & 0.25 & 0.46 & \\
\hline \multirow[t]{2}{*}{ NLR } & Death & 45 & 5.51 & 1.59 & $0.003 *$ \\
\hline & Survive & 390 & 4.12 & 1.23 & \\
\hline
\end{tabular}

who died with survival $(p>0.05)$. 
The result in Table 4 showed a significant relationship between high leukocytes of 15.16 with mortality $(p<0.05)$. The mortality rate of patients with leukocytosis (cut-off $>10,000 / \mathrm{mL}$ ) was consistent higher than patients with normal leukocyte counts. Some studies showed that the number of leukocytes in AMI patients when they arrive at the hospital could be used as an early indicator of prognosis of mortality and morbidity and AMI patients with leukocytes beginning above $15,000 / \mathrm{mL}$ had a mortality risk four times greater than leukocytes below 10,000/uL. Research results by Kurniawan et $a^{7}$ in RSWS have concluded that the average number of leukocytes in patients with AMI who died during treatment was higher compared to patients who survived and leukocytosis patients would have a risk of mortality 10.71 times compared to the normal number of leukocytes.

Table 4. Relationship of leukocytes, differential cell count

\begin{tabular}{lcccc}
\hline & & \multicolumn{2}{c}{ Exit status } & \\
\cline { 3 - 4 } \multicolumn{2}{c}{ Variable } & $\begin{array}{c}\text { Death } \\
(\mathrm{n} \%)\end{array}$ & $\begin{array}{c}\text { Survive } \\
(\mathrm{n} \%)\end{array}$ & Total \\
\hline Leukocytes & High & $35(77.8)$ & $214(54.9)$ & 249 \\
$\left(\times 10^{3} / \mu \mathrm{L}\right)$ & & & & $0.003^{*}$ \\
Neutrophils & High & $29(64.4)$ & $174(44.6)$ & 203 \\
$(\%)$ & & & & $0.012^{*}$ \\
& Low & $16(35.6)$ & $216(55.4)$ & 232 \\
Lymphocytes & High & $0(0.0)$ & $9(2.3)$ & $90.303^{*}$ \\
$(\%)$ & Low & $45(100)$ & $381(97.7)$ & 426 \\
Monocytes & High & $13(28.9)$ & $87(22.3)$ & 100 \\
$(\%)$ & & & & $0.320^{*}$ \\
& Low & $32(71.1)$ & $303(77.7)$ & 335 \\
Eosinophils & High & $1(2.2)$ & $34(8.7)$ & $350.129 *$ \\
(\%) & Low & $44(97.8)$ & $356(91.3)$ & 400 \\
Basophils (\%) & High & $30(66.7)$ & $173(44.4)$ & 203 \\
& & & & $0.005^{*}$ \\
& Low & $15(33.3)$ & $217(55.6)$ & 232 \\
\hline
\end{tabular}

Description: ${ }^{*}$ Chi-Square test

Moreover, there is a significant correlation between high neutrophils with mortality $(p<0.05)$. In this case, the relationship between lymphocytes, monocytes, eosinophils, with mortality ( $p>0.05$ ) has not been found. On the other hand, there was a significant relationship between basophil and high mortality $(p<0.05)$. As it is known that in the inflammatory process, basophil histamine as a mediator issued a major and rapid response of vascu- lar inflammation leading to local capillary vasodilation and may trigger neutrophils and monocytes to trigger inflammation.

\section{CONCLUSIONS AND SUGGESTIONS}

The conclusion of this study was that the number of leukocytes and differential leukocyte count can be used as a diagnostic marker of acute myocardial infarction between STEMI and NSTEMI and can also be used as prognostic markers among patients who died and survived.

Suggestion, further research taking regular blood samples with cohort studies in patients with AMI can avoid the bias of the obtained results.

\section{REFFERENCES}

1. World Health Organization. Prevention of Recurrences of Myocardial Infarction and Stroke Study, the PREMISE Programme: Country Projects. 2016; 820-31.

2. World Health Organization in Collaboration with the World Heart Federation and the World Stroke Organization. Global Atlas on Cardiovascular Disease Prevention and Control. 2011; 8-13.

3. The Ministry of Health of the Republic of Indonesia. Heart Health Situation. Information Center and the Ministry of Health. 2014; 1-8.

4. Aspar A, Budiono B. The Procedure Remains the Cardiovascular Care Unit Medical Services Dr. Wahidin Sudirohusodo Hospital. Raw Ministry Cardiovascular Disease. 2006; 59-69.

5. Alwi, I. Acute Miokard Infarction with ST elevation. In Textbook of Medicine. $6^{\text {th }}$ Ed., University of Indonesia Jakarta, Agency Publisher Faculty of Medicine, 2014; 1457-1474.

6. Myrta R. Pathophysiology of Acute Coronary Syndrome. World Mirror of Medicine. 2012; 39 (4): 261-4.

7. Kurniawan L.B, Bahrun U, Darmawaty, Arif M. Effect of Total Leukocytes Against Mortality in Acute Myocardial Infarction Patients During Treatment. Mirror World Medical, 2015; 42(10): 727-30.

8. Maison D. Role of Leukocytosis as Diagnostic Test added in Acute Myocardial Infarction. Semarang, Diponegoro University. 2000; 1-40.

9. Abbase AL, Khadim MAK. Leukocytes Count and Neutrophil/Lymphocytes Ratio in Predicting in-Hospital Outcome after Acute Myocardial Infarction. Medical Journal of Babylon. 2010; 7(4): 480-9. Doi: 1812-156X-7-4.

10. Gazi E, Bayram B, Gazi S, Temiz A, Kirilmaz B, Altun B, et al. Prognostic Value of the Neutrophil-Lymphocyte Ratio in Patients with ST-Elevated Acute Myocardial Infarction. Clin Appl Thromb Hemost. 2015; 21(2): 155-9. 